\title{
Automatic Generation Control of Two-Area ST- Thermal Power System using Jaya Algorithm
}

\author{
S. Bhongade**, Vishnu P Parmar** \\ *Department of Electrical Engineering, Faculty of Department of Electrical Engineering, S G S Institute of Technology \& \\ Science, Indore,23, park road, Indore-452003 M.P-INDIA \\ ** Department of Electrical Engineering, Faculty of Department of Electrical Engineering, S G S Institute of Technology \& \\ Science, Indore,23, park road, Indore-452003 M.P-INDIA \\ $\$$ Corresponding Author; S G S Institute of Technology \& Science, Indore,23, park road, Indore-452003 M.P-INDIA
}

, Tel: +91 7312582201,

Fax:+91 7312432540,bhongadesandeep@gmail.com

Received: 14.03.2018 Accepted:30.03.2018

\begin{abstract}
This article present automatic generation control (AGC) of a two area thermal system incorporating solar thermal power plant (STPP) in one of the areas. The performance of the conventional two area system is compared with the proposed system. Similarly, the performances of integral (I), proportional plus integral (PI), and proportional plus integral plus derivative (PID) controller are evaluated in the system with STPP. For optimization of the proposed system, a new optimization technique, i.e. Jaya Algorithm is used for the optimization of secondary controller gains. Examinations uncover that Jaya optimized PID controller's performance is better as compared to integral and proportional integral control. Better dynamic performances like settling time, overshoot, undershoot is achieved by Jaya algorithm for the proposed system. Further, robustness of the systems are studied by changing all the system parameter from $-25 \%$ to $25 \%$. Analysis reveals that Jaya algorithm based PID controller gains are quite robust and need not be reset for large variations in system parameters.
\end{abstract}

Keywords Automatic Generation Control, Solar Thermal Power plant, Area control error, Integral Square Error, Settling time, Over shoot, Under shoot, Jaya algorithm.

\section{Introduction}

The objective of the AGC is to make system frequency stable and tie line power deviation zero for reliable and efficient operation of the power plant. Automatic generation control plays a vital role in power systems in maintaining scheduled tie line power flow and specified frequency during the normal operating condition as well as under small perturbation [1-4].The main function of AGC is proper selection of secondary controller gain. Frequency control is the biggest issue because if frequency fluctuates in power plant, speed keeps on changing and performance of power plant will be disturbed. A Lot of work has been done earlier on AGC but their focus was on conventional generation (Thermal generation) [5-8] .These literature surveys are not based on renewable energy source and no attention has been paid to non conventional energy sources. Due to rapidly decreasing conventional energy resources and carbon emission issues, there is a need to find some other sources so that future energy demand can be met. Solar and wind energy sources are such options and solar energy has large potential. From recent studies, it is said that it has potential to be a source of the future. There are many problems with availability of non renewable energy resources, which made renewable energy sources the present research issue. Das et al. [9] Describes the concept of integration of the solar thermal power plant for AGC, but their work is limited to an isolated system only. Solar energy is the huge source of the clean energy and transformation of solar energy into electric energy does not give off greenhouse gases, also these renewable energies cut down the consumption of conventional sources of energy. Hence, automatic generation control of a multi-area system with STPP is important for further studies.

There are two control modes in AGC, primary and secondary control. Primary control is very fast and the secondary control is slow as compared to primary control. Nowadays, almost all studies on AGC are based on the 
design of the secondary controller. Many optimization methods have been studied for controller gain such as a Bacterial foraging optimization algorithm (BFOA) [10], Particle Swarm Optimization (PSO) [11], Genetic Algorithm (GA) [12], Firefly Algorithm (FA) [13], Artificial Neural Network (ANN) [14], Differential evolution (DE) [15], fuzzy logic [16], grey wolf optimization (GWO), flower pollination algorithm (FPA) and many more. All the evolutionary and swarm intelligence optimization techniques need appropriate tuning of algorithm, specific parameters in addition to tuning of common controlling parameters. The proper tuning of these parameters is very much necessary.

Improper tuning of these parameters may increase the computational cost or tendency towards the local optimal solution. Hence, to avoid tuning problems of different algorithm specific parameters, teaching learning based optimization algorithm [17] was proposed. Keeping in view good performance of the TLBO another very simple and new algorithm which is specific parameter less and flexible optimization method, i.e. JAYA ALGORITHM was proposed by R.V. Rao [18] which is quite more simpler so it is named as 'JAYA'(means triumph originated from Sanskrit),as it doesn't consider any specific algorithm parameter. Jaya algorithm considers the best and worst solution among the whole population for update [19]. So it becomes very easy and it has better convergence towards global optimum point.

Following is the main objective of this work:

(a) Modeling and integration of solar thermal power plant with two area thermal systems for AGC.

(b) Application of the Jaya algorithm for the optimization of controller gains in two area system.

(c) Comparison of dynamic responses of frequency and tie line power deviation with and without STPP to find the best solution.

(d) Comparison of integral and PI controller with PID controller.

(e) Sensitivity analysis of the system in the presence of solar thermal power plant.

\section{System Modelling}

Two area thermal power systems are considered for AGC. Value of specified parameter has been taken from [20]. In Fig. 2 Solar Thermal Power Plant is used.

\subsection{Thermal Power System}

Thermal Power System consists of two areas Area1 and Area2. Different values of parameters have been taken such as time constants and other to make the analysis realistic. Table 1 shows the transfer function of different components present in the system.
Area Control Error (ACE) is the linear combination of frequency deviation and change in tie line power. ACE is taken as input to the PID controllers.

$$
\begin{aligned}
& A C E_{1}=\Delta P_{t i e}+B_{1} \Delta w_{1} \\
& A C E_{2}=\Delta P_{t i e}+B_{2} \Delta w_{2}
\end{aligned}
$$

Where, $B_{1}=\frac{1}{R_{1}}+D_{1} \quad$ and $\quad B_{2}=\frac{1}{R_{2}}+D_{2}$

The output of the PID controllers are obtained as given below

$$
\begin{aligned}
& u_{1}=K_{P 1} A C E_{1}+K_{I 1} \int A C E_{1}+K_{D 1} \frac{d}{d t} A C E_{1} \\
& u_{2}=K_{P 2} A C E_{2}+K_{I 2} \int A C E_{2}+K_{D 2} \frac{d}{d t} A C E_{2}
\end{aligned}
$$

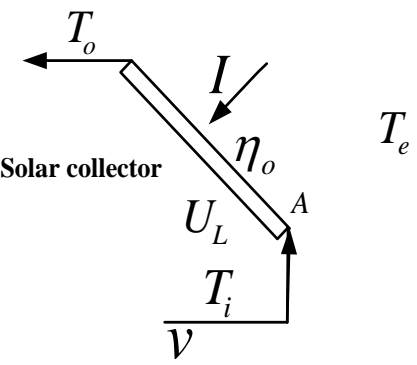

Fig. 1. Scheme of solar collector.

\subsection{Collector Model}

The derivative of output temperature is as follows

$$
\begin{aligned}
& \frac{d T_{o}(t)}{d t}=\frac{A \eta_{o}}{C} I(t)-\frac{U_{L} A}{C}\left(T_{a}(t)-T_{e}(t)\right) \\
& +\frac{v(t)}{V}\left(T_{i}(t)-T_{o}(t)\right)
\end{aligned}
$$

Time dependency of the variable are denoted as

$$
T_{a}=\left(T_{i}(t)+T_{o}(t)\right) / 2
$$

Let $v(t)$ be the constant represented as ' $v$ '. Putting Eq. (6) into the Eq. (5) and then rearranging the parameters such that output parameter is on one side and input parameter on the other side of the equation. 


$$
\begin{aligned}
& \frac{d T_{o}(t)}{d(t)}+\left(\frac{U_{L} A}{2 C}+\frac{v}{V}\right) T_{o}(t)=\frac{A \eta_{o}}{C} I(t)+\left(\frac{v}{V}-\frac{U_{L} A}{2 C}\right) T_{i}(t) \\
& +\frac{U_{L} A}{C} T_{e}(t)
\end{aligned}
$$

Taking Laplace of the above equation and the outcome of the Laplace transform is as given below.

$$
\begin{aligned}
& s T_{o}(s)-T_{o}(0)+\left(\frac{U_{L} A}{2 C}+\frac{v}{V}\right) T_{o}(s)=\frac{A \eta_{o}}{C} I(s) \\
& +\left(\frac{v}{V}-\frac{U_{L} A}{2 C}\right) T_{i}(s)+\frac{U_{L} A}{C} T_{e}(s)
\end{aligned}
$$

Rearranging above equation ...

$$
\begin{aligned}
& T_{o}(s)=\frac{T_{s}}{1+T_{s}} T_{o}(0)+\frac{T_{s}}{1+s T_{s}} \frac{A \eta_{o}}{C} I(s)+ \\
& \frac{T_{s}}{1+s T_{s}}\left(\frac{v}{V}-\frac{U_{L} A}{2 C}\right) T_{i}(s)+\frac{T_{s}}{1+s T_{s}} \frac{U_{L} A}{C} T_{e}(s)
\end{aligned}
$$

where, Ts is the time constant of the collector and given by

$$
T_{s}=\frac{1}{\frac{U_{L} A}{2 C}+\frac{v}{V}}
$$

To calculate the transfer function for a given input,

other inputs are considered and initial conditions are assumed

to be zero. The transfer function for each input is

$$
\begin{aligned}
& W_{1}(s)=\frac{T_{o}(s)}{I(s)}=\frac{T_{s}}{1+s T_{s}} \frac{A \eta_{o}}{C} \\
& W_{2}(s)=\frac{T_{o}(s)}{T_{i}(s)}=\frac{T_{s}}{1+s T_{s}}\left(\frac{v}{V}-\frac{U_{L} A}{2 C}\right)
\end{aligned}
$$

$$
W_{3}(s)=\frac{T_{o}(s)}{T_{e}(s)}=\frac{T_{s}}{\left(1+s T_{s}\right)} \frac{U_{L} A}{C}
$$

$W_{o}(s)=\frac{T_{o}(s)}{T_{o}(0)}=\frac{T_{s}}{1+s T_{s}}$

Hence the following equation gives the outlet temperature of the collector considering the effects of the inputs and the initial temperature.

$$
\begin{aligned}
& T_{o}(s)=W_{o}(s) T_{o}(s)+W_{1}(s) I(s) \\
& +W_{2}(s) T_{i}(s)+W_{3}(s) T_{e}(s)
\end{aligned}
$$

This is the collector model when the heat transfer rate is taken constant.

Various atmospheric parameters add their effects on solar collector models such as solar irradiance, inlet temperature and environment temperature, etc. But the major effect is of solar irradiance. So for simplified model only solar irradiance is considered. Hence transfer function of solar field with respect to solar irradiance is given by Eq. (15).

$$
G(s)=\frac{K_{s}}{1+T_{s} s}
$$

Where, $\mathrm{K}_{\mathrm{s}}$ is the gain value and $\mathrm{T}_{\mathrm{s}}$ is the time constant of the solar field. Hence, steam is produced in heat exchanger which drives the turbine. Solar irradiation is taken as 0.4 and transportation delay is taken for the various processes of STPP.

Table1 Component transfer function of two area system

\begin{tabular}{|l|l|}
\hline Components & Transfer Function \\
\hline Governor & $T F_{g}=1 / 1+s T_{g}$ \\
\hline Turbine & $T F_{t}=1 / 1+s T_{t}$ \\
\hline Load and machine & $1 / H s+D$ \\
\hline
\end{tabular}




\subsection{Solar Thermal Power Plant}

Renewable energy sources are current issue of research $[21,22]$. In view of system efficiency and keeping in mind the protection of the surrounding environment, renewable energy has gained the importance day by day. It is very important to reap solar energy effectively by developing solar collectors. In this article STPP has been implemented in area 1 . In addition to solar energy, transfer function of solar field has been studied [23, 24]. Solar energy has enormous potential. PV system and concentrated solar power are the systems which can produce electrical power from solar energy. The demand of CSP is growing rapidly all over the world. The main function of solar collectors is to focus the solar irradiance to the pipes that carry working fluids. Fig. 1 represent the scheme of solar collector. This hot working fluid is used to produce steam in the heat. This steam is used to drive a turbine and produce electricity.

\subsection{Fitness Function}

The Aim of Automatic Generation Control (AGC) is to make ACE zero as soon as possible. To make it possible, objective function is required for estimation of PID gain values of the proposed system.

The objective function used in this paper is ISE (integral square error) given by Eq. (16)

$$
J=\int_{0}^{t}\left\{\left(\Delta f_{i}\right)^{2}+\left(\Delta P_{t i e i-j}\right)^{2}\right\} d t
$$

$\mathrm{i}, \mathrm{j}=$ area number for $\mathrm{i}=1,2,3$ and $\mathrm{j}=2,3 \quad(j \neq i)$

The parameters are system specific and hence design problem can be obtained as

Minimize ' $\mathrm{J}$ ' i.e. objective function

Subjected to

$$
\begin{aligned}
& K_{p}^{\min } \leq K_{P} \leq K_{p}^{\max } \\
& K_{i}^{\min } \leq K_{i} \leq K_{i}^{\max } \\
& K_{d}^{\min } \leq K_{d} \leq K_{d}^{\max }
\end{aligned}
$$

\section{Jaya Algorithm}

It is a new optimization technique which can be used for future purpose. There are some reasons which made Jaya algorithm [9] useful for AGC like its flexibility, simplicity, deviation free mechanism. The main concept of this algorithm is that the solution obtained for a given problem should move towards the best solution and avoid the worst solution. The various steps involved in Jaya algorithm

Step (1): Initialization of all candidates by randomizing the variables under their boundary limits.

Step (2): Calculate the value of fitness function $f(x)$ for all candidates and identify the best and worst solution.

Step (3): Modify every candidate by altering designed variables according best and worst solution.

Step (4): Calculate $f(x)$ for each candidate after modification and then compare them with previous value; update the candidate having a better solution among them.

Step (5): Identify the new best and worst solution from updated candidates and replace with the previous one.

Step (6): Go to step second and repeat the step from 2 to 5 until the stopping condition is satisfied.

\section{Implementation of Jaya algorithm for AGC}

Initialization: Decide the no. of candidates as ' $r$ ', stopping criteria i.e. no. of iteration as's', and the no. of designing variable as ' $m$ ' i.e. gain value of the controller.

For each candidate randomize gain values.

$$
K_{i}=K_{i \min }+u\left(K_{i \max }-K_{i \min }\right)
$$

' $u$ ' is the random number $[0,1]$. Calculate the fitness value for each candidate and identify best and worst candidate.

\section{Modification:}

When initialization is over, start the iteration by setting $\mathrm{s}=1$; and modify the gain value of the controller according to the given formula

$$
\begin{aligned}
& K_{s, j, i}^{\prime}=K_{s, j, i}+u\left[\left(K_{s, b e s t, i}-\left|K_{s, j, i}\right|\right)\right] \\
& -v\left[\left(K_{s, \text { worst }, i}-\left|K_{s, j, i}\right|\right)\right]
\end{aligned}
$$

Here $\mathrm{u}$ and $\mathrm{v}$ are the random variables lies between $[0,1]$.

\section{Update:}

Calculate the fitness value of modified candidate, compare new modified fitness value with previous values for each candidate. 
If new modified fitness value is lower, then update the candidate, otherwise retain the previous values.

Again, identify new best and worst solution according to new updated fitness value.

Again perform the modification with new updated value.

\section{Stopping criteria:}

Stop algorithm when the number of iterations reaches the maximum value.

\section{Working example of Jaya algorithm:}

In order to study the working of Jaya algorithm, an objective function should be considered. Let the fitness function be the estimation of ' $a_{i}$ ' that minimize its function value.

$$
\operatorname{Min} f\left(a_{i}\right)=\sum_{i=1}^{n} a_{i}^{2}
$$

$$
\text { Subjected to " }-100 \leq a_{i} \leq 100 "
$$

Let the population size be of 5 (i.e. applicant solutions), two design variables be $a_{1}$ and $a_{2}$ and the number of end criteria be two. The initial population is arbitrarily created inside the limits of the variables and the related estimation of the fitness function is given in Table 2. Since it is a minimization function, the smallest value of $f(a)$ is taken as the best result and the largest value of $f(a)$ is taken as the most awful solution.

Table 2 Initial population

\begin{tabular}{|c|c|c|c|c|}
\hline participant & $a_{1}$ & $a_{2}$ & $f(a)$ & condition \\
\hline 1 & -4 & 17 & 305 & - \\
\hline 2 & 13 & 62 & 4013 & - \\
\hline 3 & 69 & -5 & 4786 & worst \\
\hline 4 & -7 & 6 & 85 & best \\
\hline 5 & -11 & -17 & 410 & - \\
\hline
\end{tabular}

From Table 2 it can be observed that the best solution is corresponding to the fourth applicants and the awful result is corresponding to the third applicant. Now expecting arbitrary numbers $u_{1}=0.57$ and $u_{2}=0.80$ for $a_{1}$ and $u_{1}=0.91$ and $u_{2}=0.48$ for $a_{2}$, the new estimation of the variables for $a_{1}$ and $a_{2}$ are estimated using Eq. (19) and putting in Table 2. For instance for the first applicants, the new estimated value of $a_{1}$ and $a_{2}$ during the first iteration are calculated as shown below.

$$
\begin{aligned}
& a_{n, r, i}^{\prime}=a_{n, r, i}+u_{1}\left(a_{n, \text { best }, i}-\left|a_{n, r, i}\right|\right) \\
& -u_{2}\left(a_{n, \text { worst }, i}-\left|a_{n, r, i}\right|\right) \\
& a_{1,1,1}^{,}=a_{1,1,1}+u_{1}\left(a_{1,4,1}-\left|a_{1,1,1}\right|\right) \\
& -u_{2}\left(a_{1,3,1}-\left|a_{1,1,1}\right|\right) \\
& \quad=-4+0.57(-7-|-4|)-0.80(69-|-4|)=-62.27 \\
& \begin{array}{c}
a_{2,1,1}=a_{2,1,1}+u_{1}\left(a_{2,4,1}-\left|a_{2,1,1}\right|\right) \\
-u_{2}\left(a_{2,3,1}-\left|a_{2,1,1}\right|\right) \\
=17+0.91(6-|17|)-0.48(-5-|17|)=17.55
\end{array}
\end{aligned}
$$

Also, the new estimation of $a_{1}$ and $a_{2}$ for the other participants is computed. Table 3 demonstrates the new estimation of $a_{1}$ and $a_{2}$ and the corresponding values of the fitness function.

Table 3 New values of the factors and fitness function after first iteration

\begin{tabular}{|l|l|l|l|}
\hline participant & $a_{1}$ & $a_{2}$ & $f(a)$ \\
\hline 1 & -62.27 & 17.55 & 4185.5554 \\
\hline 2 & -43.2 & 43.2 & 3732.48 \\
\hline 3 & 25.68 & 0.71 & 659.9665 \\
\hline 4 & -64.58 & 11.28 & 4297.8148 \\
\hline 5 & & & \\
\hline
\end{tabular}

Presently, the estimations of $f(a)$ of Tables 2 and 3 are found out and the best estimations of $f(a)$ are taken and put in Table 4. This finishes the primary emphasis of the Jaya algorithm. 
Table 4 Updated values of the factors and the fitness function in view of fitness comparison at the end of first iteration.

\begin{tabular}{|l|l|l|l|l|}
\hline participant & $a_{1}$ & $a_{2}$ & $f(a)$ & condition \\
\hline 1 & -4 & 17 & 305 & - \\
\hline 2 & -43.2 & 43.2 & 3732.48 & worst \\
\hline 3 & 25.68 & 0.71 & 659.9665 & - \\
\hline 4 & -7 & 6 & 85 & best \\
\hline 5 & -11 & -17 & 410 & - \\
\hline
\end{tabular}

From Table 4 it can be observed that the best result is corresponding the fourth applicant and the awful result is corresponding to the second applicant. Now, amid the second iteration, let arbitrary numbers ' $u_{1}=0.26$ and $u_{2}=0.22$ ' for $a_{1}$ and ' $u_{1}=0.37$ and $u_{2}=0.50$ ' for $a_{2}$, the new estimation of the variables for ${ }^{a_{1}}$ and $a_{2}$ are estimated using Eq. (19). Table 5 demonstrates the new estimation of $a_{1}$ and $a_{2}$, the corresponding values of the fitness function amid the second iteration.

Table 5 Modified values of candidates after second iteration

\begin{tabular}{|l|l|l|l|}
\hline participant & $a_{1}$ & $a_{2}$ & $f(a)$ \\
\hline 1 & 3.524 & -0.17 & 12.4474 \\
\hline 2 & -37.244 & 29.436 & 2253.6 \\
\hline 3 & 32.3368 & -18.5777 & 1390.8 \\
\hline 4 & 0.404 & -12.6 & 158.93 \\
\hline 5 & & & 1181.6964 \\
\hline
\end{tabular}

The obtained solution of $f(a)$ of Tables 4 and 5 are taken and the best estimation of $f(a)$ are considered and set in Table 6. This finishes the second iteration of the Jaya algorithm.

From Table 6 it can be observed that the favorable result is corresponding to the first participant and the worst result is corresponding to the second applicant. It can also be seen that the estimated result of the fitness function is decreased from 85 to 12.4474 in only two cycles. Again, if we add up the number of iterations, then the known values of the fitness function (i.e. 0) can be acquired within a few numbers of iterations. Likewise, in the case of maximization problems, the best value infers the maximum measure of the fitness function and the computations are to be continued with as need be. In this way, the proposed strategy can manage both minimization and maximization issues.

Table 6 Final updated values of the factors of the candidates after second iteration

\begin{tabular}{|l|l|l|l|l|}
\hline participant & $a_{1}$ & $a_{2}$ & $f(a)$ & condition \\
\hline 1 & 3.524 & -0.17 & 12.4474 & best \\
\hline 2 & -37.24 & 29.436 & 2253.6 & worst \\
\hline 3 & 25.68 & 0.71 & 659.9665 & - \\
\hline 4 & -7 & 6 & 85 & - \\
\hline 5 & -11 & -17 & 410 & - \\
\hline
\end{tabular}

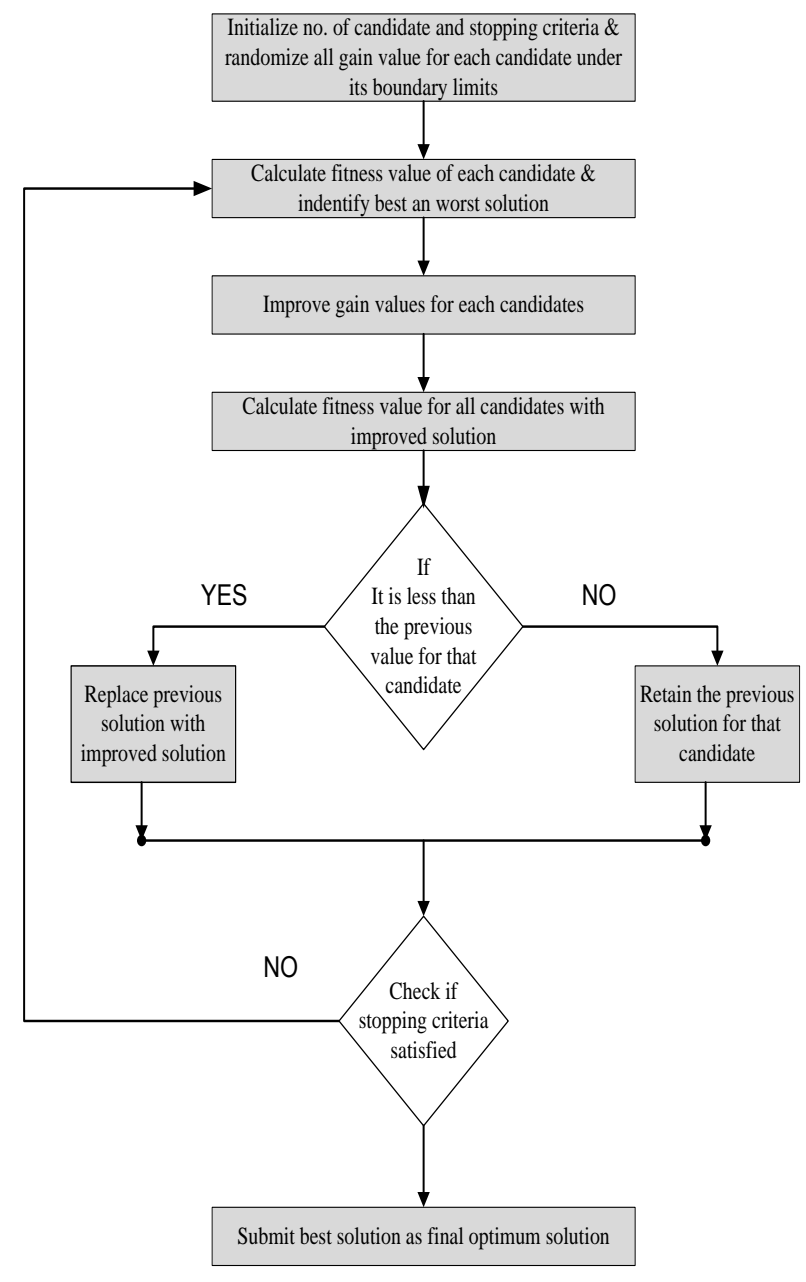

Fig4 Flow chart of best candidate updating 


\section{Simulation Results and Discussion}

The dynamic performance of the proposed system is compared with two area thermal systems at step load perturbation of $0.2 \mathrm{pu}$ in both the area using Jaya algorithm. Fig. 5 shows the convergence curve for the proposed system. Frequency deviation in area1, area 2 and tie line power deviation are shown in the Fig.6, 7 and 8 respectively. Table7 shows the PID gains for both the system. Result shows that power plant with solar power gives quick settlement of frequency and power deviation to zero. From the Fig. 6-8 it is clear that Jaya algorithm based PID controlled for the two area power system with STPP gives better dynamic response when subjected to sudden increase in the power demand. Settling time $\left(T_{s}\right)$, peak undershoots $\left(U_{s h}\right)$ and peak overshoots $\left(O_{s h}\right)$ of $\Delta \omega_{1}, \Delta \omega_{2}$ and $\Delta P_{\text {tie }}$ are shown in Table 8 . From Table 8 it is easily observed that settling times, undershoots and overshoots of frequency and tie-line power deviation are less with the proposed framework as compared to two area thermal systems using Jaya algorithm. A clear pictorial view of settling time, undershoots and overshoots are shown in Figs. 9-11, respectively.

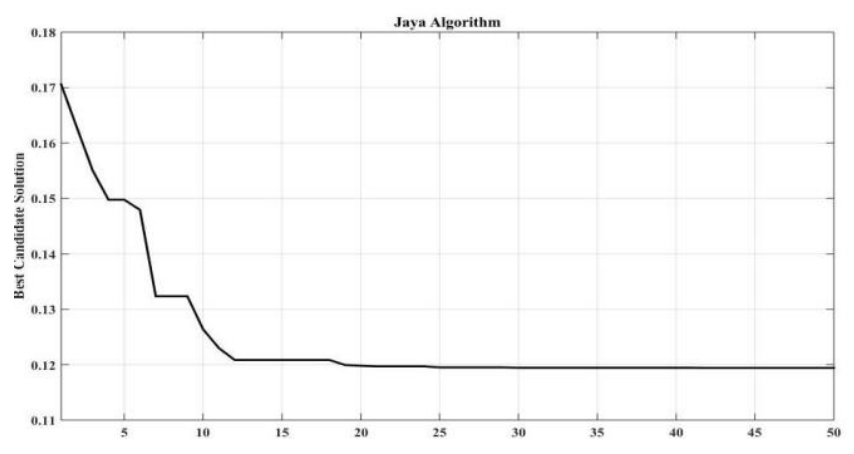

Fig.5 Best candidate solution with STPP

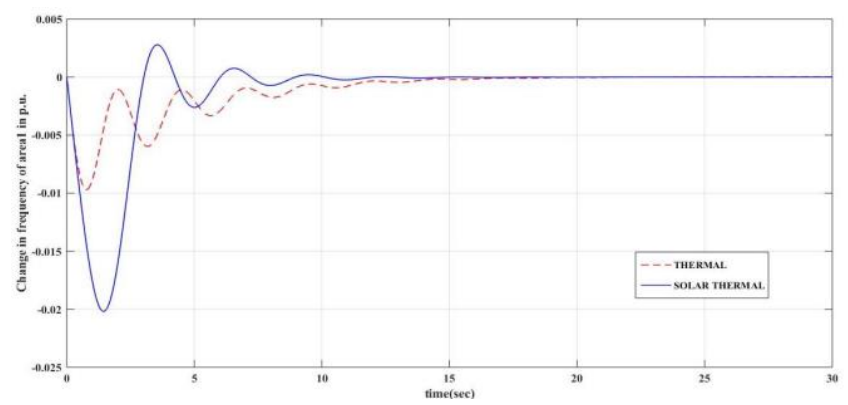

Fig. 6. Frequency deviation of area1 with \& without STPP

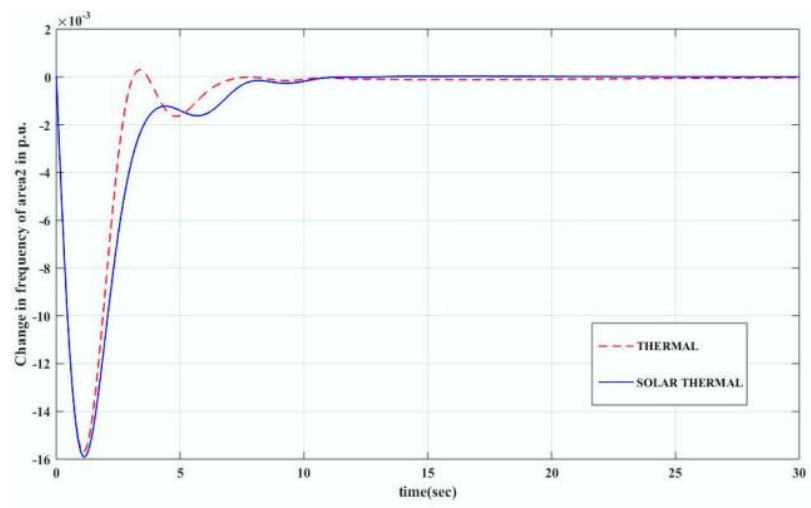

Fig. 7. Frequency deviation of area 2 with \& without STPP

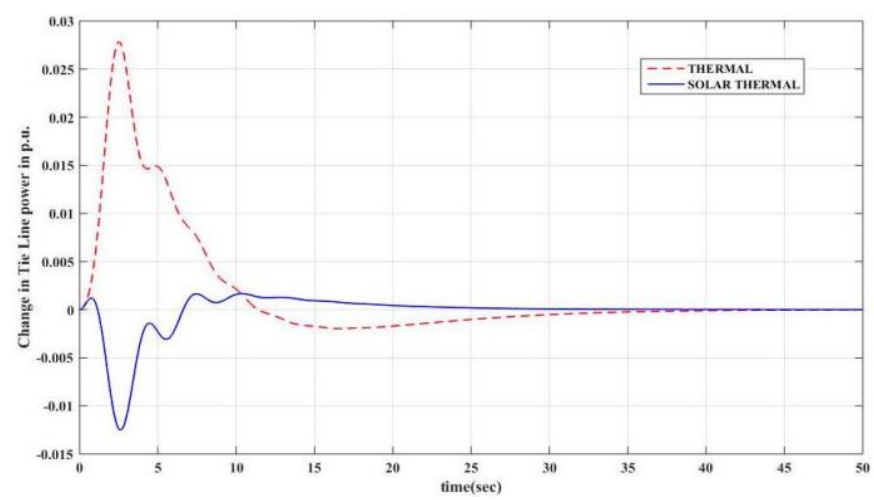

Fig.8. Tie line power with and without STPP.

Table 7 Controller gains with and without STPP

\begin{tabular}{|c|c|c|}
\hline Controller gain & Without STPP & With STPP \\
\hline $\mathrm{K}_{\mathrm{p} 1}$ & 0.9067 & 0 \\
\hline $\mathrm{K}_{\mathrm{p} 2}$ & 1 & 0.3539 \\
\hline $\mathrm{K}_{\mathrm{i} 1}$ & 0.7798 & 0.3197 \\
\hline $\mathrm{K}_{\mathrm{i} 2}$ & 1 & 1 \\
\hline $\mathrm{K}_{\mathrm{d} 1}$ & 1 & 0.2560 \\
\hline $\mathrm{K}_{\mathrm{d} 2}$ & 0.9015 & \\
\hline
\end{tabular}

Table 10 Controller gain values with variation in SLP

\begin{tabular}{|c|c|c|}
\hline Controller gain & $0.2 \mathrm{pu}$ SLP & $0.3 \mathrm{pu}$ SLP \\
\hline $\mathrm{K}_{\mathrm{p} 1}$ & 1 & 1 \\
\hline $\mathrm{K}_{\mathrm{p} 2}$ & 0 & 0.3373 \\
\hline $\mathrm{K}_{\mathrm{i} 1}$ & 0.3539 & 0.3039 \\
\hline $\mathrm{K}_{\mathrm{i} 2}$ & 0.3197 & 1 \\
\hline $\mathrm{K}_{\mathrm{d} 1}$ & 1 & 0.1852 \\
\hline $\mathrm{K}_{\mathrm{d} 2}$ & 0.2560 & \\
\hline
\end{tabular}


Table 8 Dynamic performance with and without STPP

\begin{tabular}{|c|c|c|c|}
\hline Parameters & $\begin{array}{l}\text { Dynamic } \\
\text { performanc } \\
\text { e }\end{array}$ & $\begin{array}{l}\text { Without } \\
\text { STPP }\end{array}$ & With STPP \\
\hline \multirow{3}{*}{$\Delta \mathrm{w}_{1}$} & $\begin{array}{l}\text { Settling } \\
\text { time }\end{array}$ & 15.256776 & 8.5291308 \\
\hline & Over shoot & 0.002817183 & $\begin{array}{l}0.00278648 \\
7\end{array}$ \\
\hline & $\begin{array}{l}\text { Under } \\
\text { shoot }\end{array}$ & $\begin{array}{l}0.009684018 \\
5\end{array}$ & $\begin{array}{l}0.02018847 \\
3\end{array}$ \\
\hline \multirow{3}{*}{$\Delta \mathrm{w}_{2}$} & $\begin{array}{l}\text { Settling } \\
\text { time }\end{array}$ & 8.2250906 & 7.5307438 \\
\hline & Over shoot & $\begin{array}{l}0.000195577 \\
12\end{array}$ & $\begin{array}{l}0.00003422 \\
029\end{array}$ \\
\hline & $\begin{array}{l}\text { Under } \\
\text { shoot }\end{array}$ & $\begin{array}{l}0.009007382 \\
8\end{array}$ & $\begin{array}{l}0.01590833 \\
1\end{array}$ \\
\hline \multirow{3}{*}{$\Delta \mathrm{P}_{\text {tie }}$} & $\begin{array}{l}\text { Settling } \\
\text { time }\end{array}$ & 37.552106 & 22.898826 \\
\hline & Over shoot & $\begin{array}{l}0.005357803 \\
3\end{array}$ & 0.00167344 \\
\hline & $\begin{array}{l}\text { Under } \\
\text { shoot }\end{array}$ & $\begin{array}{l}0.002412772 \\
3\end{array}$ & $\begin{array}{l}0.01251335 \\
8\end{array}$ \\
\hline
\end{tabular}

Table 9 Comparison of Integra, PI controller with PID using Jaya algorithm for STPP

\begin{tabular}{|l|l|l|l|l|}
\hline $\begin{array}{l}\text { Parame } \\
\text { ters }\end{array}$ & $\begin{array}{l}\text { Dynamic } \\
\text { performa } \\
\text { nce }\end{array}$ & Integral & PI control & $\begin{array}{l}\text { PID } \\
\text { control }\end{array}$ \\
\hline \multirow{8}{*}{$\Delta \mathrm{W}_{1}$} & $\begin{array}{l}\text { Settling } \\
\text { time }\end{array}$ & 11.92054 & 14.41872 & 8.5291308 \\
\cline { 2 - 5 } & $\begin{array}{l}\text { Over } \\
\text { shoot }\end{array}$ & $\begin{array}{l}0.012924 \\
503\end{array}$ & $\begin{array}{l}0.002328 \\
1984\end{array}$ & 0.0027864 \\
& $\begin{array}{l}\text { Under } \\
\text { shoot }\end{array}$ & $\begin{array}{l}0.025128 \\
898\end{array}$ & $\begin{array}{l}0.020845 \\
056\end{array}$ & 0.0201884 \\
\cline { 2 - 5 } & & & 73 \\
\hline
\end{tabular}

\begin{tabular}{|l|l|l|l|l|}
\hline \multirow{5}{*}{$\Delta \mathrm{w}_{2}$} & $\begin{array}{l}\text { Settling } \\
\text { time }\end{array}$ & $\begin{array}{l}14.65804 \\
7\end{array}$ & $\begin{array}{l}13.97882 \\
7\end{array}$ & 7.5307438 \\
\cline { 2 - 5 } & $\begin{array}{l}\text { Over } \\
\text { shoot }\end{array}$ & $\begin{array}{l}0.002179 \\
5308\end{array}$ & $\begin{array}{l}0.001641 \\
0739\end{array}$ & $\begin{array}{l}0.0000342 \\
2029\end{array}$ \\
\cline { 2 - 5 }$\Delta \mathrm{P}_{\text {tie }}$ & $\begin{array}{l}\text { Under } \\
\text { shoot }\end{array}$ & $\begin{array}{l}0.018085 \\
167\end{array}$ & $\begin{array}{l}0.019666 \\
237\end{array}$ & $\begin{array}{l}0.0159083 \\
31\end{array}$ \\
\hline \multirow{5}{*}{$\begin{array}{l}\text { Settling } \\
\text { time }\end{array}$} & $\begin{array}{l}24.37099 \\
4\end{array}$ & $\begin{array}{l}31.00917 \\
1\end{array}$ & 22.898826 \\
\cline { 2 - 5 } & $\begin{array}{l}\text { Over } \\
\text { shoot }\end{array}$ & $\begin{array}{l}0.014122 \\
517\end{array}$ & 0.004050 & 0.0016734 \\
& 3251 & 4 \\
\cline { 2 - 5 } & $\begin{array}{l}\text { Under } \\
\text { shoot }\end{array}$ & $\begin{array}{l}0.045736 \\
824\end{array}$ & $\begin{array}{l}0.008765 \\
3243\end{array}$ & $\begin{array}{l}0.0125133 \\
58\end{array}$ \\
\hline
\end{tabular}

\section{Sensitivity analysis}

For sensitivity analysis the parameters and loading condition of the system are changed and controller gains are optimized using Jaya algorithm. The dynamic responses corresponding to these changes are obtained and compared with the result with the dynamic responses at nominal condition. It is essential for a robust controller that response should be more or less same and there must be no need to reset the controller. In the present work, sensitivity analysis is performed to confirm the robustness of the system with STPP at nominal condition and parameters. To accomplish the analysis, system parameter is changed from ' $-25 \%$ to $+25 \%$ ' and SLP is changed to $0.2 \mathrm{pu}$ and $0.3 \mathrm{pu}$.For every changed condition the Jaya algorithm is used. Table10 and Table11 give the complete dynamic response of the proposed system for SLP and parameter variation when sensitivity analysis is performed. By observing the responses, it is very clear that obtained responses more or less are same. Thus, it is not necessary to change the gains of the PID at nominal to large change in system parameter and system loading condition. That means Jaya optimized PID controlled AGC with STPP is quite robust towards variation in the system over a wide range. 


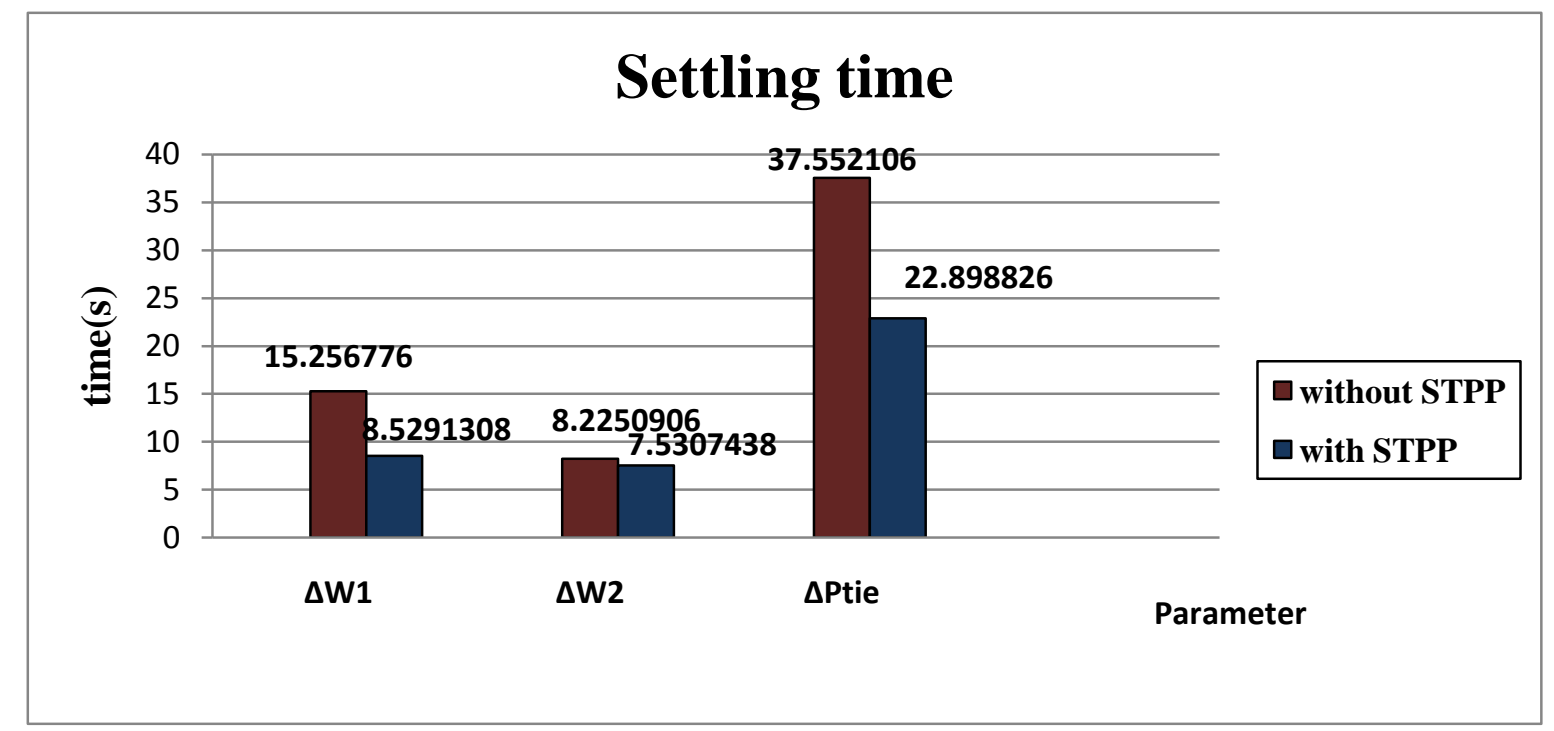

Fig.9 Settling time variation with and without STPP

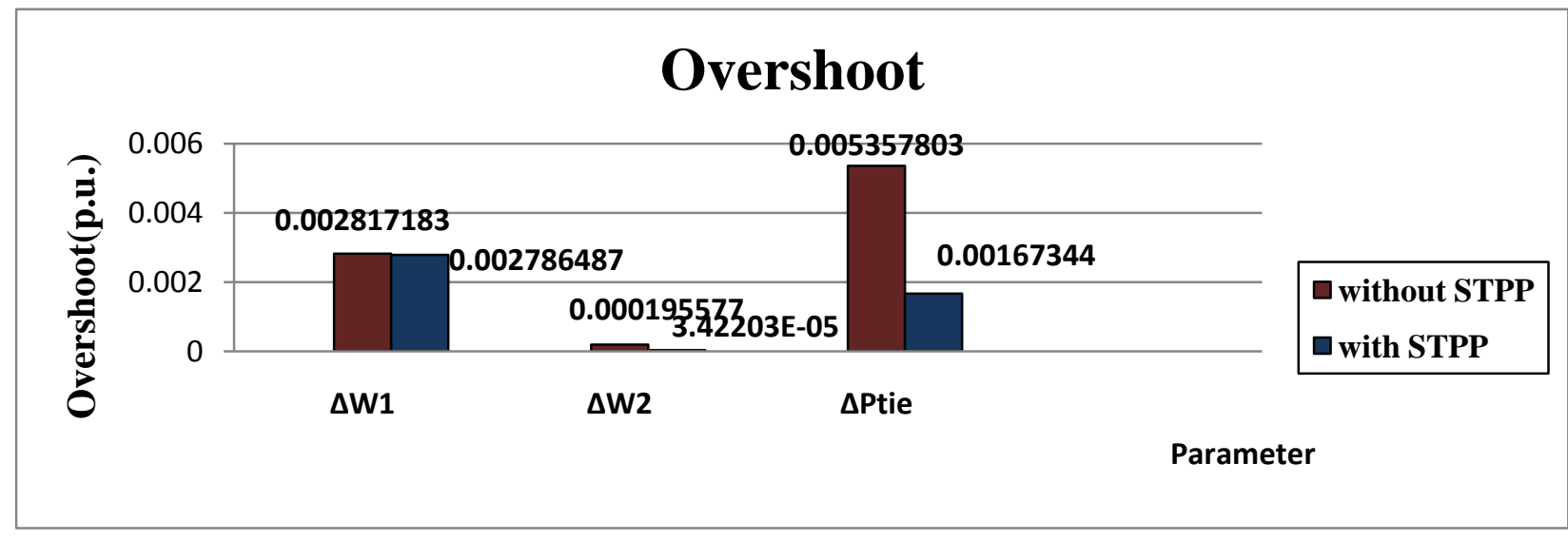

Fig. 10 Overshoot bar graph comparisons with and without STPP.

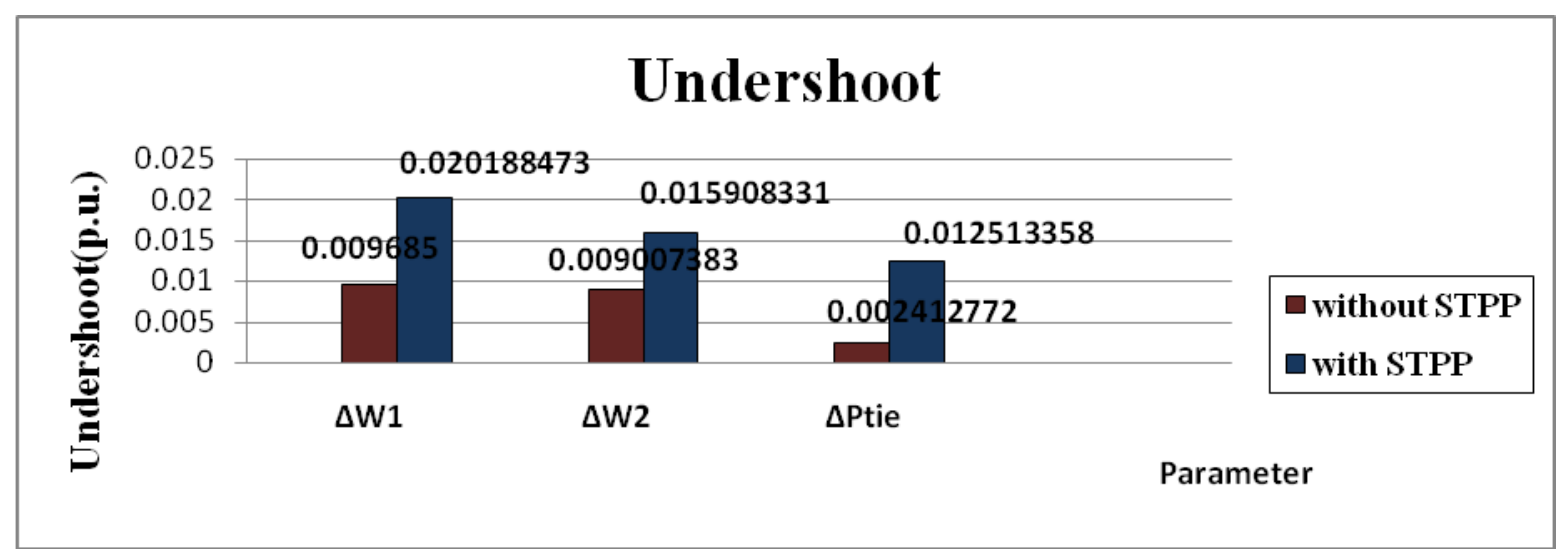

Fig.11 Undershoot bar graph comparisons with and without STPP. 
INTERNATIONAL JOURNAL Of SMART GRID

S. Bhongade and V. P. Parmar, Vol.2, No.2, 2018

Table 11 Variation of dynamic response due to parameter variation

\begin{tabular}{|c|c|c|c|c|c|c|c|c|c|c|}
\hline \multirow[b]{2}{*}{ parameter } & \multirow{2}{*}{$\begin{array}{l}\% \\
\text { change }\end{array}$} & \multicolumn{3}{|l|}{$\Delta w 1$} & \multicolumn{3}{|l|}{$\Delta w 2$} & \multicolumn{3}{|l|}{$\Delta P_{\text {tir }}$} \\
\hline & & Tsh & Osh & Ush & Tsh & Osh & Ush & Tsh & Osh & Ush \\
\hline \multirow[b]{2}{*}{ H1 } & $-25 \%$ & 9.967 & 0.00378 & 0.023727 & 9.99 & 0.000026 & 0.017494 & 20.940134 & 0.00240236 & 0.01464 \\
\hline & $+25 \%$ & 7.843218 & 0.0023124974 & 0.01774943 & 7.6773387 & 0.000057 & 0.014045275 & 24.536005 & 0.0031159903 & 0.012141874 \\
\hline \multirow[b]{2}{*}{ H2 } & $-25 \%$ & 8.447504 & 0.00329 & 0.02031574 & 7.1903782 & 0.000055 & 0.014995355 & 22.042253 & 0.0033296802 & 0.016895385 \\
\hline & $+25 \%$ & 8.4718598 & 0.0026352639 & 0.019951027 & 7.7642598 & 0.000478 & 0.015618253 & 25.364941 & 0.0020970231 & 0.010781626 \\
\hline \multirow[b]{2}{*}{ B1 } & $-25 \%$ & 9.1284712 & 0.003147332 & 0.021114225 & 9.8274345 & 0.000045 & 0.015275278 & 22.536033 & 0.0028675887 & 0.019748915 \\
\hline & $+25 \%$ & 8.1568069 & 0.0027468093 & 0.019345793 & 7.2142669 & 0.000023 & 0.015085191 & 19.846182 & 0.0014140686 & 0.011864722 \\
\hline \multirow[b]{2}{*}{ B2 } & $-25 \%$ & 8.6601691 & 0.0026837065 & 0.020178607 & 9.4541039 & 0.00004 & 0.015311252 & 18.909338 & 0.0020493035 & 0.015182851 \\
\hline & $+25 \%$ & 8.6860817 & 0.0025852562 & 0.020200881 & 9.6689652 & 0.000012 & 0.015541179 & 21.386598 & 0.0018671772 & 0.014848399 \\
\hline \multirow{3}{*}{ R1 } & $-25 \%$ & 10.438101 & 0.008650002 & 0.02003173 & 11.850764 & 0.000661 & 0.010027439 & 21.669692 & 0.0054400836 & 0.015981231 \\
\hline & $+25 \%$ & 8.9902774 & 0.0028079957 & 0.02082685 & 9.7952811 & 0.000051 & 0.015283233 & 23.261783 & 0.002474558 & 0.018501153 \\
\hline & $-25 \%$ & 11.437101 & 0.0099500018 & 0.019403173 & 13.748764 & 0.000502 & 0.011047439 & 22.639682 & 0.0063248836 & 0.025981111 \\
\hline R2 & $+25 \%$ & 9.7295637 & 0.0030324743 & 0.020172373 & 7.1730084 & 0.000585 & 0.016606628 & 27.42467 & 0.001952615 & 0.0083626957 \\
\hline \multirow{2}{*}{ Tt1 } & $-25 \%$ & 6.8343678 & 0.0022591771 & 0.0189408 & 6.7699531 & 0.000099 & 0.014782653 & 27.920121 & 0.0019045057 & 0.010543049 \\
\hline & $+25 \%$ & 12.149776 & 0.0039474897 & 0.021261441 & 10.583439 & 0.000005 & 0.016943349 & 18.472651 & 0.0027113535 & 0.014908602 \\
\hline \multirow[b]{2}{*}{ Tt2 } & $-25 \%$ & 8.6735947 & 0.0026346944 & 0.020188579 & 9.5685389 & 0.000023 & 0.015414931 & 20.587431 & 0.0019878199 & 0.014996786 \\
\hline & $+25 \%$ & 8.4416353 & 0.0028348692 & 0.020177253 & 7.487368 & 0.000045 & 0.016165546 & 25.444204 & 0.0016714428 & 0.010398255 \\
\hline \multirow[b]{2}{*}{ Tg1 } & $-25 \%$ & 7.9997093 & 0.0017949551 & 0.019562933 & 7.535956 & 0.000032 & 0.015742732 & 23.415229 & 0.0013005842 & 0.010898016 \\
\hline & $+25 \%$ & 11.528843 & 0.0035601232 & 0.020816417 & 10.058958 & 0.000023 & 0.016412503 & 20.461281 & 0.0024131651 & 0.013639974 \\
\hline \multirow[b]{2}{*}{ Tg2 } & $-25 \%$ & 8.5556907 & 0.0028410849 & 0.020164081 & 7.6799391 & 0.000039 & 0.015471428 & 23.076302 & 0.0019452797 & 0.013691793 \\
\hline & $+25 \%$ & 8.4606812 & 0.0029495722 & 0.020183418 & 7.3824903 & 0.000045 & 0.016144485 & 25.215021 & 0.0019252055 & 0.011469311 \\
\hline
\end{tabular}




\section{Conclusion}

In this paper renewable energy source that is solar thermal power plant (STPP) is incorporated with two area automatic generation control system and also a new optimization technique i.e. Jaya algorithm is used. It was also concluded that after using solar power in area one, the dynamic performance of the framework is improved compared to without STPP. Jaya algorithm is used for the first time in Automatic Generation Control for optimization of several parameters such as gain value of the PID controller. Comparison of performance of classical controller such as integral (I), proportional integral (PI), proportional integral derivative (PID) reveals that the PID controller gives better result with STPP. It is also found that the dynamic response of the system with STPP is improved from the view point of settling time, peak overshoot, undershoot and magnitude of the oscillations. From sensitivity analysis point of the system, it is found that Jaya algorithm based PID controller gains obtained at specified condition and specified system parameters is quite robust and it is not necessary to reset parameter for large variations in the system and other system parameters.

\section{References}

[1] Elgerd O1. Fosha C,'Optimal megawatt frequency control of multi area electric energy systems", IEEE Trans Electric Power Apparatus System, vol.PAS-89, pp.556-63, 1970.

[2] C. Fosha and O. I. Elgerd, "The megawatt-frequency control problem: A new approach via optimal control theory," IEEE Trans. Power Apparatus \& Systems, vol. PAS-89, no. 4, pp.563-577, Apr. 1970.

[3] O.I. Elgard"Electrical Energy System Theory: An Intro, 2nd Ed", New York: McGraw Hill, 1982. [BOOK].

[4] M. L. Kothari and J. Nanda, "Application of optimal control strategy to automatic generation control of a hydrothermal system", IEE Proceedings, vol. 135, no.4, Jul. 1988.

[5] Abido MA, “ AGC Tuning Of Interconnected Reheat Thermal Systems With Particle Swarm Optimization", IEEE Trans Energy Conversion;17(3):406-13,2003.

[6] J. Nanda, A. Mangal and S. Suri, "Some New Findings on Automatic Generation Control of an Interconnected Hydrothermal System With Conventional Controllers", IEEE Trans. on Energy Conversion, vol. 21, no. 1, Mar. 2006.

[7] Gayadhar Panda, Sidhartha Panda and C. Ardil," Hybrid Neuro Fuzzy Approach for Automatic Generation Control of Two -Area Interconnected Power System”,Int J Electr Power Energy Syst;59:19-35, 2009.
[8] Saikia Lalit Chandra, Nanda J, Mishra S, "Performance comparison of Several classical controllers in AGC for multi-area interconnected thermal system", Int J Electr Power Energy Syst;33(3):394-401, 2011.

[9] Das Dulal Ch,Sinha N, Roy Ak, "GA based frequency controller for solar thermal-diesel, wind hybrid energy generation/energy storage system", Int J Electr Power Energy Syst;43(1):262-79.2012.

[10] J.Nanda, S.Mishra and L.C.Saikia, "Maiden Application of Bacterial Foraging Based Optimization Technique in Multiarea Automatic Generation Control", IEEE Transactions on Power Systems, vol. 22, No.2, pp.602609, 2009.

[11] Praghnesh Bhatt. Roy R. Ghoshal S.P., "GA/particle swarm intelligence based optimization of two specific varieties of controller devices applied to two-area multiunits automatic generation control", Electrical Power and Energy Systems; 32: 299-310; 2010.

[12]H. Golpira, H. Barvani, "Application of GA optimization for automatic generation control design in an interconnected power system", Energy Conversion and Management; 52: 2247- 2255, 2011.

[13]LC Saikia. "Automatic Generation Control of a combined cycle gas turbine plant with classical controllers using firefly algorithm", International Journal of Electrical Power and Energy Systems, vol.53, pp. 2733, 2013.

[14] Shashi Kant Pandey, Soumya R. Mohanty, Nand Kishor . "A literature survey on load-frequency control for conventional and distribution generation power systems". Renewable and Sustainable Energy Reviews, 25:318-334, 2013.

[15]Banaja Mohanty, Sidhartha Panda , P.K. Hota, "Controller parameters tuning of differential evolution algorithm and its application to load frequency control of multisource power system", Electrical Power and Energy Systems; 54: 77-85, 2014.

[16] Hassan A. Yousef, Khalfan AL-Kharusi, Mohammed H. Albadi. "Load Frequency Control of a Multi-Area Power System: An Adaptive Fuzzy Logic Approach". IEEE Transaction on Power System,vol.29,No. 4, Jul. 2014.

[17] Rao, R.V., Savsani, V.J. \&Vakharia, D.P., “ Teachinglearning-based optimization: A novel method for constrained mechanical design optimization problems". Computer-Aide Design, 43(3), 303-315, 2011. 
[18] Rao RV. "Jaya: A simple and new optimization algorithm for solving constrained and unconstrained optimization problems". Int J Ind Engg Comput ;7(1):19e34, 2016.

[19]R.V. Rao, D.P. Rai,Joze Balic, “A multi-objective algorithm for optimization of modern machining processes". Engineering Applications of Artificial Intelligence; 61:103-125, 2017.

[20]Binod Kumar Sahu, Swagat Pati, Pradeep Kumar Mohanty, Sidharth Panda, "Teaching - learning based optimization algorithm based fuzzy-PID Controller form automatic generation control of multi-area power System", Int JElectr Power Energy Syst;48:19- 32,2014.

[21] Reddy VSiva, Kaushik SC, Ranjan KR, Tyagi SK. "State-of-the-art of solar thermal power plants-a review”. Renew Sust Energy Rev, 27:258-73, 2013.

[22] Fontalvo Armando, Garcia Jesus, Sanjuan Marco, Vasquez Padilla Ricardo. "Automatic control strategies for hybrid solar-fossil fuel power plants". Renewable Energy; 62:424- 31, 2014.

[23] Buz'as J, Kicsiny R, "Transfer functions of solar collectors for dynamical analysis and control design", Renewable Energy;68:146-55, 2014.

[24] Yatin Sharma, Lalit Chandra Saikia. "Automatic generation control of multi- area STThermal power system using Grey Wolf Optimizer algorithm based classical controllers". Electrical Power and Energy Systems; 73,853-862,2015.

[25] Jagatheesan K., Anand B., Baskaran K., Dey N., Ashour A., Balas V. (2018) Effect of Nonlinearity and Boiler Dynamics in Automatic Generation Control of Multiarea Thermal Power System with Proportional-IntegralDerivative and Ant Colony Optimization Technique. In: Kyamakya K., Mathis W., Stoop R., Chedjou J., Li Z. (eds) Recent Advances in Nonlinear Dynamics and Synchronization. Studies in Systems, Decision and Control, vol 109. Springer, Cham.

[26] SasmitaPadhy,SidharthaPanda, "A hybrid stochastic fractal search and pattern search technique based cascade PI-PD controller for automatic generation control of multi-source power systems in presence of plug in electric vehicles", CAAI Transactions on Intelligence Technology, Volume 2, Issue 1, March 2017, Pages 12-25.

[27] Tapabrata Chakraborty; David Watson; Marianne Rodgers, "Automatic Generation Control Using an
Energy Storage System in a Wind Park", IEEE Transactions on Power Systems, Vol. 33, No. 1, January 2018.

[28] M. Del Castillo, G. P. Lim, Y. Yoon, and B. Chang, "Application of frequency regulation control on the 4 MW/8 MWh battery energy storage system (BESS) in Jeju Island, Republic of Korea," J. Energy Power Sources, vol. 1, no. 6, pp. 287-295, 2014.

[29]Lei Zhang; Yi Luo $^{1}$; Jing Ye ; Ya-yuan Xiao , "Distributed coordination regulation marginal cost control strategy for automatic generation control of interconnected power system", IET Generation, Transmission \& Distribution, Volume 11, Issue 6, 20 April 2017, p. 1337 - 1344.

[30] Satya Dinesh Madasu, M.L.S. Sai Kumar, Arun Kumar Singh, Comparable Investigation of Backtracking Search Algorithm in Automatic Generation Control for Two Area Reheat Interconnected Thermal Power System, (2017), http://dx.doi.org/10.1016/j.asoc.2017.01.018.

[31] Debdeep Saha and Lalit Chandra Saikia, "Automatic generation control of a multi-area CCGT-thermal power system using stochastic search optimised integral minus proportional derivative controller under restructured environment", IET Generation, Transmission \& Distribution, Volume 11, Issue 15, 19 October 2017 , p. $3801-381$.

[32] Arya, Y., Kumar, N.: 'AGC of a multi-area multi-source hydrothermal power system interconnected via AC/DC parallel links under deregulated environment', Int. J. Electric. Power Energy Syst., 2016, Vol 75, pp. 127138. 